\title{
STOCHASTIC MODELLING FOR DYNAMICS OF INTERACTING POPULATIONS
}

\author{
Jevgenijs Carkovs and Oksana Pavlenko ${ }^{\#}$
}

Rīga Technical University, 1 Kaḷku Str., Rīga, LV-1658, LATVIA

\# Corresponding author oksana.pavlenko@rtu.Iv

Contributed by Jevgeniijs Carkovs

The paper deals with a mathematical model for two interacting populations. Under the assumption of fast stochastic contacting of populations, we derive stochastic Poisson-type differential equations with a small parameter and propose an approximative algorithm for quantitative analysis of population dynamics that consists of two steps. First, we derive an ordinary differential equation for mean value of each population growth and analyse the average asymptotic population behaviour. Then, applying diffusion approximation procedure, we derive a stochastic Ito differential equation for small random deviations on the average motion in a form of a linear nonhomogeneous Ito stochastic differential equation and analyse the probabilistic characteristics of the Gaussian process given by this equation.

Key words: diffusion approximation, stochastic population dynamics.

\section{INTRODUCTION}

The most popular classical mathematical model for interacting populations mostly is given (Lotka, 1925; Volterra, 1931; Bazykin, 1998; Murray, 2003; Britton, 2005; Edelstein-Keshet, 2005) as a system of ordinary differential equations:

$$
\left\{\begin{array}{l}
\frac{d x}{d t}=x f(x)+g(x, y), \\
\frac{d y}{d t}=y h(y)+m(x, y),
\end{array}\right.
$$

where $x$ and $y$ are the densities of interacting populations, the functions $f(x)$ and $h(y)$ define the relative growth rates of the populations in the absence of interactions, sufficiently smooth functions $g(x, y)$ and $m(x, y)$ are the changes of populations growth rates conditioned on a cooperative effect, called "functional responses". In reality, even though all functions of the right-hand side in (1) are derived in compliance with biological laws, the parameters of these functions are random and should be estimated by collecting and analysing environmental data. Therefore, several papers propose and analyse mathematical models for interacting populations in a form of stochastic Ito differential equations (Mangel and Ludwig, 1977; Samanta, 2011):

$$
\left\{\begin{aligned}
& d x(t)=[x(t) f(x(t))+g(x(t), y(t))] d t+ \\
& \sigma_{1}(x(t), y(t)) d w_{1}(t), \\
& d y(t)=[y(t) h(x(t))+m(x(t), y(t))] d t+ \\
& \sigma_{2}(x(t), y(t)) d w_{2}(t)
\end{aligned}\right.
$$

where $w_{1}(t)$ and $w_{2}(t)$ are correlated Wiener processes given on a probability space $(\Omega, \mathcal{F}, \mathrm{P})$. Like the deterministic model (1) the above mentioned stochastic models suppose fixed contacts of the interacting populations. The mathematical model for population dynamics discussed in our paper is also given as a system of stochastic differential equations, but of the Poisson type rather than Ito (Skorokhod, 1989). To introduce our model, we first need to specify a stationary Poisson process $\{\xi(t), t \geq 0\}$ on the probability space $(\Omega, \mathcal{F}, \mathrm{P})$ with the generator (Gikhman and Skorokhod, 1972):

$$
\begin{aligned}
Q v(z):=\lim _{s \downarrow 0} \frac{1}{s} E\{v(\xi(t+s))-v(z) / \xi(t) & =z\}= \\
& =\frac{1}{\varepsilon} \int_{U}(v(u)-v(z)) \pi(d u),
\end{aligned}
$$

where $U \subset R, \pi(d u)$, is a probabilistic measure on $\left\{U, \Sigma_{U}\right\}$ and $v(u)$ is an arbitrary bounded measurable function. This process satisfies a stochastic Skorokhod type differential equation:

$d \xi(t)=\int_{U}(u-\xi(t-)) \mu_{\varepsilon}(d t, d u)$ 
where $\mu_{\varepsilon}(d t, d u)$ is a Poisson measure (Skorokhod, 1989) on $R \times U$ with parameter $\varepsilon^{-1} \pi(d u) d t$. Here and hereinafter in this paper we will use notation $f(t-)$ for the left limit of a function $f(\cdot)$ at a point $t$, that is, $f(t-):=\lim f(t-s)$. The increments of this process we will use ${ }^{s} \Upsilon_{i k e}$ increments of a Wiener process for deriving stochastic Ito equations. The dynamics of a piecewise constant process $\{\xi(t), t \geq 0\}$ with the previously defined generator may be specified as follows (Gikhman and Skorokhod, 1972): there exists such a stationary time series of independent exponentially distributed with parameter $\varepsilon^{-1}$ random variables $\left\{\delta_{k-1}, k \in N\right\}$ and independent on this sequence stationary time series $\left\{\xi_{k}, k \in N\right\}$ with distribution $\pi(d u)$ that $\xi(t) \equiv \varsigma_{k-1}$ at any time interval $\tau_{k-1}<t<\tau_{k}$ and $\xi\left(\tau_{k}\right)=\varsigma_{k}$, where $\tau_{k}=\tau_{k-1}+\delta_{k-1}, \tau_{0}=0$. By definition the mean value of the time interval $\left(\tau_{k-1}, \tau_{k}\right)$ is equal to $\varepsilon$ and hence for sufficiently small $\varepsilon>0$ the previously defined Poisson process like a Wiener process also has fast oscillations. The proposed stochastic model for interacting populations of preys $x_{\varepsilon}(t)$ and predators $y_{\varepsilon}(t)$ may be specified as a system of stochastic Poisson type differential equations:

$$
\left\{\begin{aligned}
d x_{\varepsilon}(t)=\left[x_{\varepsilon}(t)\right. & \left.\left.f\left(x_{\varepsilon}(t)\right)+g_{\varepsilon}(t), y_{\varepsilon}(t)\right)\right] d t+ \\
& +\varepsilon \int_{U} G\left(x_{\varepsilon}(t), y_{\varepsilon}(t), \tilde{\mu}_{\varepsilon}(d t, d u),\right. \\
\left.d y_{\varepsilon}(t)=\left[y_{\varepsilon}(t) h\left(y_{\varepsilon}(t)\right)+m_{\varepsilon}(t), y_{\varepsilon}(t)\right)\right] d t+ & \\
& +\varepsilon \int_{U} M\left(x_{\varepsilon}(t), y_{\varepsilon}(t), \tilde{\mu}_{\varepsilon}(d t, d u),\right.
\end{aligned}\right.
$$

where $G(x, y, u)$ and $M(x, y, u)$ are sufficiently smooth functions and $\tilde{\mu}_{\varepsilon}(d t, d u)$ is a centered Poisson measure defined by the equality $\tilde{\mu}_{\varepsilon}(d t, d u)=\mu_{\varepsilon}(d t, d u)-\varepsilon^{-1} \pi(d u) d t$. The third terms on the right-hand side of equations (2) are results of possible random perturbations. Note that the integrals

$$
\begin{aligned}
& \eta(t)=\varepsilon \int_{0}^{t} \int_{U} G\left(x_{\varepsilon}(t-), y_{\varepsilon}(t-), u\right) \tilde{\mu}_{\varepsilon}(d t, d u), \\
& \chi(t)=\varepsilon \int_{0}^{t} \int_{U} M\left(x_{\varepsilon}(t-), y_{\varepsilon}(t-), u\right) \tilde{\mu}_{\varepsilon}(d t, d u),
\end{aligned}
$$

define the Poisson martingales with independent increments (Mangel and Ludwig, 1977).

In the second and third sections we describe the method for approximative analysis of the system (2) proposed in (Skorokhod, 1989; Tsarkov, 2002). This method, the same as the classical limit theorem, consists of two steps: the averaging procedure and the Gaussian approximation for deviations from the mean value. The fourth section is devoted to analysis of the most popular models (Murray, 2003; Bazykin, 1998) for population interaction.

\section{STOCHASTIC AVERAGING PROCEDURE}

Probabilistic properties for the Markov process defined by equations (2) may be specified (Gikhman and Skorokhod, 1972) by the weak infinitesimal operator

$$
\begin{aligned}
L(\varepsilon) v(x, y) & =\lim _{\Delta \rightarrow 0} \frac{1}{\Delta} E\left\{v\left(x_{\varepsilon}(t+\Delta), y_{\varepsilon}(t+\Delta)\right)-\right. \\
& \left.-v\left(x_{\varepsilon}(t), y_{\varepsilon}(t)\right) / x_{\varepsilon}(t)=x, y_{\varepsilon}(t)=y\right\}= \\
& =\frac{d^{+}}{d t} E\left\{v\left(x_{\varepsilon}(t), y_{\varepsilon}(t)\right) / x_{\varepsilon}(t)=x, y_{\varepsilon}(t)=y\right\},
\end{aligned}
$$

where $v(x, y)$ is an arbitrary sufficiently smooth function and $\frac{d^{+}}{d t}$ is the right derivative.

To derive this operator, we can apply the Skorokhod formula (Gikhman and Skorokhod, 1972) for the change of variables and specify the above operator (4) by the formula

$$
\begin{aligned}
& L(\varepsilon) v(x, y)=[x f(x)+g(x, y)] \frac{\partial}{\partial x} v(x, y)+ \\
& \quad+[y h(y)+m(x, y)] \frac{\partial}{\partial y} v(x, y)+ \\
& \quad+\int_{U}[v(x+\varepsilon G(x, y, u), y+\varepsilon M(x, y, u))-v(x, y)] \pi(d u)- \\
& \quad-\int_{U}\left[G(x, y, u) \frac{\partial}{\partial x} v(x, y)+M(x, y, u) \frac{\partial}{\partial y} v(x, y)\right] \pi(d u) .
\end{aligned}
$$

Now we can take the limit in (5) as $\varepsilon \rightarrow 0$ and derive the operator

$$
\begin{array}{r}
L v(x, y):=\lim _{\varepsilon \rightarrow 0} \frac{1}{\varepsilon} L(\varepsilon) v(x, y)=\left[\begin{array}{c}
x f(x)+g(x, y)] \frac{\partial}{\partial x} v(x, y)+ \\
{[y h(y)+m(x, y)] \frac{\partial}{\partial y} v(x, y) .}
\end{array}\right.
\end{array}
$$

This means (Skorokhod, 1989) that we can be sure that for any $\delta>0, r>0, T>0$

$\left.\lim _{\varepsilon \rightarrow 0} \sup _{\left(x_{0} y_{o}\right) \in S_{r}} P \sup _{0 \leq t \leq T}\left(\left|x_{\varepsilon}(t)-x(t)\right|+\left|y_{\varepsilon}(t)-y(t)\right|\right)>\delta\right)=0$,

where $\{x(t), y(t)\}$ is the solution of (1), $S_{r}$ is a centered circle in $R^{2}$ and $x_{0} y_{0}$ are initial conditions for (1) and (2). This guarantees that for any $T>0$ and any initial conditions $x_{\varepsilon}(0)=x(0)=x, y_{\varepsilon}(0)=y(0)=y$ we may be sure that

$\lim _{\varepsilon \rightarrow 0} \sup _{0 \leq t \leq T} E\left\{\left|x_{\varepsilon}(t)-x(t)\right|+\left|y_{\varepsilon}(t)-y(t)\right|\right\}=0$

The ordinary differential equation (1) mostly can be used for qualitative analysis of the population growth in the mean. If the dynamical system (1) has an attracting set, then we can rely on a population being located in some neighborhood of this attracting set. But in reality, even such small random perturbations as (2) can significantly change population dynamics and the attracting set turns into a repulsive set. Only if an asymptotically stable equilibrium point $(\bar{x}, \bar{y})$ for dynamical system (1) satisfies identities $G(\bar{x}, \bar{y}, u) \equiv 0$, $M(\bar{x}, \bar{y}, u) \equiv 0$ we may be sure (Tsarkov, 2002) that this point is asymptotically stable equilibrium for dynamical system (2) with probability one.

\section{DIFFUSION APPROXIMATION}

According to the diffusion approximation method for impulsive Markov dynamical systems (Skorokhod, 1989) to analyse random deviations for solutions of initial equations (2) on solutions of averaging equations (1), at first we have to derive the stochastic differential equations for the two-dimensional non-homogeneous Markov process

$X_{\varepsilon}(t):=\frac{x_{\varepsilon}(t)-x(t)}{\sqrt{\varepsilon}}, Y_{\varepsilon}(t):=\frac{y_{\varepsilon}(t)-y(t)}{\sqrt{\varepsilon}}$, 
derive a weak infinitesimal operator $\mathfrak{L}_{t}(\varepsilon)$ dependent on $\varepsilon$ and $t$ for this process and take on the limit as $\varepsilon \rightarrow 0$. It can be easily ensured that we may derive stochastic equations for (6) accurate within infinitesimal order greater than $\varepsilon$. Therefore, the differentials for processes (6) may be derived as follows:

$$
\begin{aligned}
& d X_{\varepsilon}(t)=\frac{1}{\sqrt{\varepsilon}}\left[d x_{\varepsilon}(t)-d x(t)\right]= \\
& =\frac{1}{\sqrt{\varepsilon}}\left[\left(x(t)+\sqrt{\varepsilon} X_{\varepsilon}(t)\right) f\left(x(t)+\sqrt{\varepsilon} X_{\varepsilon}(t)\right)+\right. \\
& \left.+g\left(x(t)+\sqrt{\varepsilon} X_{\varepsilon}(t), y(t)+\sqrt{\varepsilon} Y_{\varepsilon}(t)\right)\right] d t+ \\
& +\sqrt{\varepsilon} \int_{U} G\left(x(t)+\sqrt{\varepsilon} X_{\varepsilon}(t), y(t)+\sqrt{\varepsilon} Y_{\varepsilon}(t), u\right) \tilde{\mu}_{\varepsilon}(d t, d u)- \\
& -\frac{1}{\sqrt{\varepsilon}}[f(x(t)+g(x(t), y(t))] d t]=\left\{\left[f(x(t))+x(t) f^{\prime}(x(t))+\right.\right. \\
& \left.\left.\left.+g_{x}^{\prime}(x(t), y(t))\right] X_{\varepsilon}(t)+g_{y}^{\prime}(x(t), y(t))\right] Y_{\varepsilon}(t)\right\} d t+ \\
& +\sqrt{\varepsilon} \int_{U} G(x(t), y(t), u) \tilde{\mu}_{\varepsilon}(d t, d u)+ \\
& +\varepsilon \int_{U}\left[G_{x}^{\prime}(x(t), y(t), u) X_{\varepsilon}(t)+\right. \\
& \left.+G_{y}^{\prime}(x(t), y(t), u) Y_{\varepsilon}(t)\right] \tilde{\mu}_{\varepsilon}(d t, d u)+o(\varepsilon), \\
& d Y_{\varepsilon}(t)=\frac{1}{\sqrt{\varepsilon}}\left[d y_{\varepsilon}(t)-d y(t)\right]= \\
& =\frac{1}{\sqrt{\varepsilon}}\left[d y(t)+\sqrt{\varepsilon} Y_{\varepsilon}(t)\right) h\left(y(t)+\sqrt{\varepsilon} Y_{\varepsilon}(t)\right)+m(x(t)+ \\
& \left.\left.+\sqrt{\varepsilon} X_{\varepsilon}(t), y(t)+\sqrt{\varepsilon} Y_{\varepsilon}(t)\right)\right] d t+ \\
& +\sqrt{\varepsilon} \int_{U} M\left(x(t)+\sqrt{\varepsilon} X_{\varepsilon}(t), y(t)+\sqrt{\varepsilon} Y_{\varepsilon}(t), u\right) \tilde{\mu}_{\varepsilon}(d t, d u)- \\
& \left.-\frac{1}{\sqrt{\varepsilon}}[y(t) h(y(t))+m(x(t)), y(t))\right] d t= \\
& =\left\{\left[h(y(t))+y(t) h^{\prime}(y(t))+m_{y}^{\prime}(x(t), y(t))\right] Y_{\varepsilon}(t)+\right. \\
& \left.+m_{x}^{\prime}(x(t), y(t)) X_{\varepsilon}(t)\right\} d t+\sqrt{\varepsilon} \int_{U} M(x(t), y(t), u) \tilde{\mu}_{\varepsilon}(d t, d u)+ \\
& +\varepsilon \int_{U} M_{x}^{\prime}(x(t), y(t), u) X_{\varepsilon}(t)+ \\
& \left.+M_{y}^{\prime}(x(t), y(t), u) Y_{\varepsilon}(t)\right] \tilde{\mu}_{\varepsilon}(d t, d u)+o(\varepsilon) .
\end{aligned}
$$

By definition (6) equations (7)-(8) have zero initial conditions. Next, applying Ito-Skorokhod substitution formula (Gikhman and Skorokhod, 1972), we can derive a weak infinitesimal operator for the non-homogeneous Markov process (6) in asymptotic form:

$\mathfrak{L}_{t}(\varepsilon) v(X, Y)=\overline{\mathfrak{L}}_{t} v(X, Y)+O(\sqrt{\varepsilon})$,

where the operator

$$
\begin{aligned}
& \overline{\mathcal{L}}_{t} v(X, Y)=\left\{\left[f(x(t))+x(t) f^{\prime}(x(t))+g_{x}^{\prime}(x(t), y(t))\right] X \frac{\partial}{\partial X}+\right. \\
& \left.\quad+g_{y}^{\prime}(x(t), y(t))\right] Y \frac{\partial}{\partial X}+\left[h(y(t))+y(t) h^{\prime}(y(t))+\right. \\
& \left.\left.\quad+m_{y}^{\prime}(x(t), y(t))\right] Y \frac{\partial}{\partial Y}+m_{x}^{\prime}(x(t), y(t))\right] X \frac{\partial}{\partial Y}+ \\
& \quad+\frac{1}{2} \int_{U} \mid G\left(x(t),\left.y(t)\right|^{2} \pi(d u) \frac{\partial^{2}}{\partial X^{2}}+\right. \\
& \quad+\frac{1}{2} \int_{U} \mid M\left(x(t), y(t),\left.u\right|^{2} \pi(d u) \frac{\partial^{2}}{\partial Y^{2}}+\right. \\
& \left.\quad+\int_{U} G(x(t), y(t), u) M(x(t), y(t), u) \pi(d u) \frac{\partial^{2}}{\partial X \partial Y}\right\} v(X, Y)
\end{aligned}
$$

may be considered (Skorokhod, 1989) as a weak infinitesimal operator for the non-homogeneous two-dimensional Markov process $\vec{Z}(t):=\left(\begin{array}{l}X(t) \\ Y(t)\end{array}\right)$ given on some probability space $(\tilde{\Omega}, \tilde{\mathcal{F}}, \tilde{P})$ defined by stochastic Ito differential equation:

$d \vec{Z}(t)=A(x(t), y(t)) \vec{Z}(t) d t+\sum(x(t), y(t)) d \vec{w}(t)$,

where $\vec{w}(t)$ is the two-dimensional Wiener processes with identity covariance matrix,

$$
\begin{gathered}
\begin{array}{c}
a_{11}(t)=f(x(t))+x(t) f^{\prime}(x(t), y(t))+g_{x}^{\prime}(x(t), y(t)), \\
a_{12}(t)=g_{y}^{\prime}(x(t), y(t)),
\end{array} \\
\begin{array}{r}
a_{21}(t)=m_{x}^{\prime}(x(t), y(t)), \\
a_{22}(t)=h(y(t))+y(t) h^{\prime}(y(t))+m_{y}^{\prime}(x(t), y(t)), \\
A(x(t), y(t))=\left(\begin{array}{ll}
a_{11}(t) & a_{12}(t) \\
a_{21}(t) & a_{22}(t)
\end{array}\right), \\
\Sigma(x(t), y(t))=\left(\begin{array}{ll}
\sigma_{11}(t) & \sigma_{12}(t) \\
\sigma_{21}(t) & \sigma_{22}(t)
\end{array}\right),
\end{array}
\end{gathered}
$$

and the matrix $\Sigma(t)$ is a solution of matrix equation

$\Sigma(x(t), y(t)) \Sigma^{\mathrm{T}}(x(t), y(t))=S(x(t), y(t))$,

where

$$
\begin{aligned}
& S(x(t), y(t))=\left(\begin{array}{ll}
s_{11}(t) & s_{12}(t) \\
s_{21}(t) & s_{22}(t)
\end{array}\right), \\
& s_{11}(t)=\int_{U} G\left(x(t), Y(t),\left.u\right|^{2} \pi(d u),\right. \\
& s_{22}(t)=\int_{U} M\left(x(t), Y(t),\left.u\right|^{2} \pi(d u),\right. \\
& s_{12}(t)=\int_{U} G(x(t), y(t), u) M(x(t), y(t), u) \pi(d u) .
\end{aligned}
$$

Recall that the functions $\{X 9 t), y(t)\}$ are the solutions of equation (1) with the initial condition $x(0)=x_{\varepsilon}(0)=x$, $y(0)=y_{\varepsilon}(0)=y$ and the Markov process defined by (9) starts at the point (0.0). It can be easily to ensured that $\{\vec{Z}(t), t \in R\}$ is a two dimensional zero-mean Gaussian process and its covariance matrix $C(t)$ satisfies the matrix differential equations:

$$
\begin{array}{r}
\frac{d}{d t} C(t)=A(x(t), y(t)) C(t)+C(t) A^{T}(x(t), y(t))+ \\
+S(x(t), y(t))
\end{array}
$$

with the zero initial condition. If $(\bar{x}, \bar{y})$ is an asymptotically stable equilibrium point for (1), then the coefficients in (9) are constant matrices and we may write a solution of this equation with any initial conditions $\vec{Z}\left(t_{0}\right)$ for any $t_{0} \in R$ as follows:

$$
\begin{aligned}
\vec{Z}\left(t, t_{0}\right)=\exp \left\{-A(\bar{x}, \bar{y})\left(t-t_{0}\right)\right. & \vec{Z}\left(t_{0}\right)+ \\
& +\int_{t_{0}}^{t} \exp \{-A(\bar{x}, \bar{y})(t-s)\} d \vec{w}(s) .
\end{aligned}
$$

The matrix $A(\bar{x}, \bar{y})$ as the Jacobian matrix for (1) at the stable equilibrium point $(\bar{x}, \bar{y})$ is negative definite. Therefore, 
with probability one there exists satisfying (9) a Markov process

$$
\vec{Z}_{\text {stac }}(t)=\lim _{t_{0} \rightarrow-\infty} \vec{Z}+\left(t, t_{0}\right)=\int_{-\infty}^{t} \exp \{-A(\bar{x}, \bar{y})(t-s)\} d \vec{w}(s)
$$

and the finite dimensional distributions for any solution of (9) converge to the correspondent distributions for this stationary Gaussian Markov process. The constant covariance matrix $\bar{C}$ for $\vec{Z}_{\text {stac }}(t)$ may be derived as the solution of matrix equation

$A(\bar{x}, \bar{y}) \bar{C}+\bar{C} A^{T}(\bar{x}, \bar{y})=-S(\bar{x}, \bar{y})$

This means that if $(\bar{x}, \bar{y})$ is a stable equilibrium point for (1), then there exists such a neighbourhood $V_{r}:=\left\{\bar{x} \in R^{2}\right.$ : $\left.|x-\bar{x}|^{2}+|y-\bar{y}|^{2}<r\right\}$ of this point that for any $\vec{x}_{\varepsilon}(0)=$ $\vec{x}(0) \in V_{r}$ and sufficiently small $\varepsilon>0$, the finite dimensional distributions of the solution of equation (2) may be (Mangel and Ludwig, 1977; Skorokhod, 1989) approximated by the finite dimensional distributions of the two dimensional non-homogeneous Gaussian Markov process $\{\vec{x}(t)+$ $\left.\sqrt{\varepsilon} \vec{Z}_{\text {stac }}(t)\right\}$. Unfortunately, for other asymptotically stable attracting sets the solution of equation (10) can unrestrictedly increase and we may apply the previously constructed diffusion approximation at a sufficiently small time interval only. For example, if $\vec{x}_{\varepsilon}(t):=\{\hat{x}(t), \hat{y}(t)\}$ is an asymptotically stable limit cycle for (1) with period $w$, then all matrices in (10) are $w$-periodic and we can expect a resonance effect for this equation.

\section{STOCHASTIC MODELS FOR LOGISTIC POPULA- TIONS WITH RANDOM FUNCTIONAL RESPONSES}

In this section we illustrate capabilities of diffusion approximation procedure derived in the previous section to analysis of stochastic models for interpopulation relationship of two interacting populations: symbiosis, competition and praypredator. The deterministic mathematical models for dynamical analysis of these models for the first time appear in papers by Lotka, 1925, and Volterra, 1931. Denoting the mass density of the first species by $x(t)$ and the mass density of the second species by $y(t)$ at time moment $t$, the above authors assume that the dynamics of populations may be studied as the system of ordinary differential equations:

$\left\{\begin{array}{l}\frac{d x(t)}{d t}=g_{1} x(t)-g_{2} x^{2}(t)+g_{3} x(t) y(t) \\ \frac{d y(t)}{d t}=m_{1} y(t)-m_{2} y^{2}(t)+m_{3} x(t) y(t)\end{array}\right.$

where terms $g_{1} x(t)-g_{2} x^{2}(t)$ and $m_{1} y(t)-m_{2} y^{2}(t)$ are the growth rates of the two populations in the absence of interpopulation contacts. The terms $g_{3} x(t) y(t)$ and $m_{3} x(t) y(t)$, called the functional responses, reflect an effect of contacts on the population growth. The classical mathematical biology uses the following classification:

1. protocooperation: all parameters in (11) are positive;

2. competition: $g_{1}>0, g_{2}>0, g_{3}<0, m_{1}>0, m_{2}>0, m_{3}<0$
3. prey-predator: $g_{1}>0, g_{2}>0, g_{3}<0, m_{1}<0, m_{2}=0$, $m_{3}>0$

In compliance with our approach for stochastic modelling we suppose random interpopulation contacts at random time moments. For that we assume the coefficients of functional responses to be perturbed by jump type Poisson martingales and define the Poisson stochastic model for interacting populations as follows:

$$
\left\{\begin{array}{c}
d x_{\varepsilon}(t)=\left[g_{1} x_{\varepsilon}(t)+g_{2} x_{\varepsilon}^{2}(t)+g_{3} x_{\varepsilon}(t) y_{\varepsilon}(t)\right] d t+ \\
\varepsilon \int_{U} a(u) x_{\varepsilon}(t) y_{\varepsilon}(t) \tilde{\mu}_{\varepsilon}(d u, d t) . \\
d y_{\varepsilon}(t)=\left[m_{1} y_{\varepsilon}(t)+m_{2} y_{\varepsilon}^{2}(t)+m_{3} x_{\varepsilon}(t) y_{\varepsilon}(t)\right] d t+ \\
\varepsilon \int_{U} b(u) x_{\varepsilon}(t) y_{\varepsilon}(t) \tilde{\mu}_{\varepsilon}(d u, d t) .
\end{array}\right.
$$

where $\tilde{\mu}_{\varepsilon}(d u, d t)$ is the centred Poisson measure defined in the first section, $a(u)$ and $b(u)$ are bounded measurable functions,

$\int_{U} a^{2}(u) \pi(d u)=\delta_{1}^{2}, \int_{U} b^{2}(u) \pi(d u)=\delta_{2}^{2}$,

$\int_{U} a(u) b(u) \pi(d u)=\delta_{12}$.

The first step for approximative diffusion approximation method is qualitative analysis of equations (11). It is not so difficult to find a nontrivial coordinate of the equilibrium point for this system:

$\bar{x}=\frac{g_{1} m_{2}+g_{3} m_{1}}{g_{2} m_{2}-m_{3} g_{3}}, \bar{y}=\frac{g_{1} m_{3}+g_{2} m_{1}}{m_{2} g_{2}-m_{3} g_{3}}$.

If $g_{2} m_{2}>m_{3} g_{3}$, then these coordinates are positive, that is, both populations coexist. The Jacobian for the dynamical system (11) at the point (13) has the following form:

$A(\bar{x}, \bar{y})=\left(\begin{array}{cc}-g_{2} \bar{x} & g_{3} \bar{x} \\ m_{3} \bar{y} & -m_{2} \bar{y}\end{array}\right)$

The trace of this matrix is negative, and the determinant is positive. Therefore, if the equilibrium (13) has positive coordinates, then, according to classical mathematical model (11) both populations coexist at some neighbourhood of the equilibrium (13). Figures 1,2 and 3 show trajectories of equations (11) and (12) for $\varepsilon=0.01$, the Uniform $U(-1 ; 1)$ distribution $\pi(d u), a(u)=2 u, b(u)=u$, the initial values $x(0)=y(0)=3$ and the parameters specially selected for the type of interaction.

Now we can analyse the normalized deviations (6) using the diffusion approximation process $\vec{Z}(t)=\left(\begin{array}{l}X(t) \\ Y(t)\end{array}\right)$ that satisfies stochastic differential equation (9). For our examples this equation has the following form:

$d \vec{Z}(t)=A(x(t), y(t)) \vec{Z}(t) d t+\Sigma(x(t), y(t)) d \vec{w}(t)$,

where $\{x(t), y(t)\}$ is the solution of equations (11) with initial conditions $x(0)=x_{\varepsilon}(0), y(0)=y_{\varepsilon}(0), \vec{w}(t)$ is two-dimensional Wiener processes with identity covariance matrix, 


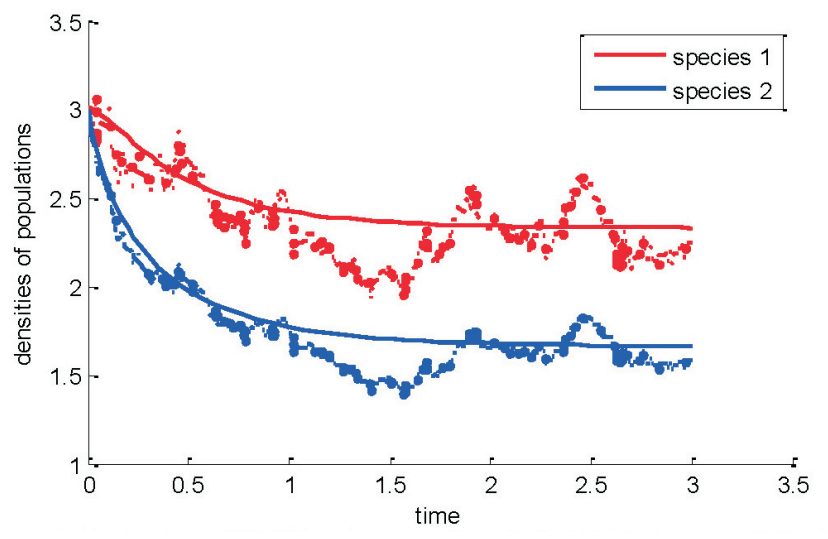

Fig. 1. The systems (11)-(12) protocooperation: $\mathrm{g} 1=3$; $\mathrm{g} 2=2$; $\mathrm{g} 3=1$; $\mathrm{m} 1=1 ; \mathrm{m} 2=2 ; \mathrm{m} 3=1$

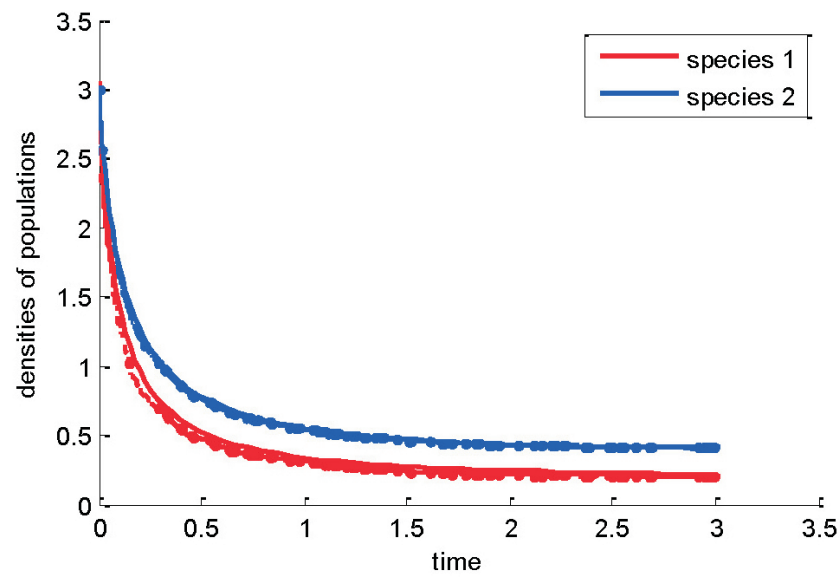

Fig. 2. The systems (11)-(12) concurrence: $\mathrm{g} 1=1 ; \mathrm{g} 2=3 ; \mathrm{g} 3=-1 ; \mathrm{m} 1=1$; $\mathrm{m} 2=2 ; \mathrm{m} 3=-1$

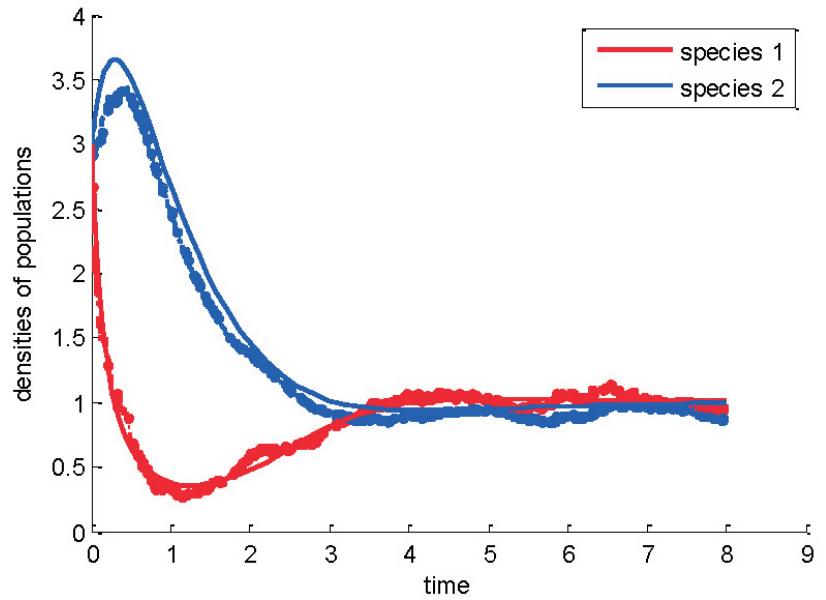

Fig. 3. The systems (11)-(12) prey-predator: $\mathrm{g} 1=3$; $\mathrm{g} 2=2$; $\mathrm{g} 3=-1$; $\mathrm{m} 1=-1 ; \mathrm{m} 2=0 ; \mathrm{m} 3=1$

$A(x(t), y(t))=\left(\begin{array}{cc}-g_{2} x(t) & g_{3} x(t) \\ m_{3} y(t) & -m_{2} y(t)\end{array}\right)$,

the matrix $\Sigma(t)$ is the solution of the matrix equation

$\Sigma(x(t), y(t)) \Sigma^{\mathrm{T}}(x(t), y(t))=S(x(t), y(t))$,

and
$S(x(t), y(t))=\frac{2}{3}\left(\begin{array}{cc}a^{2} x^{2}(t) & a b x(t) y(t) \\ a b x(t) y(t) & a^{2} y^{2}(t)\end{array}\right)$.

As a function of time, the covariance matrix $C(t)$ for the Gaussian process $\vec{Z}(t)$ satisfies the ordinary matrix differential equation

$$
\begin{array}{r}
\frac{d}{d t} C(t)=A(x(t), y(t)) C(t)+C(t) A^{T}(x(t), y(t))+ \\
+S(x(t), y(t))
\end{array}
$$

with the zero initial conditions. Now we can approximate the distribution for solutions of equations (12) $\left\{x_{\varepsilon}(t), y_{\varepsilon}(t)\right\}$ at any time moment by the Gaussian distribution of the process $\{x(t)+\sqrt{\varepsilon} X(t), y(t)+\sqrt{\varepsilon} Y(t)\}$ Figures 4,5 and 6 show the trajectories $\{x(t)+\sqrt{\varepsilon} X(t), y(t)+\sqrt{\varepsilon} Y(t)\}$ for $\varepsilon=0.01$, the Uniform $U(-1 ; 1)$ distribution $\pi(d u), a(u)=2 u, b(u)=u$, the initial values $x(0)=y(0)=3$ and the parameters specially selected for the type of interaction.

Defined by equations (14), coordinates $\left\{q_{11}(t), q_{12}(t), q_{22}(t)\right\}$ of the symmetric matrix-function $C(t)$ are shown on Figures 7,8 , and 9 .

As we can see, for any population there exists an asymptotically stable equilibrium $\bar{C}$ for equation (14). Recall that the solution $\{x(t), y(t)\}$ of equation (11) for selected parameters tends to equilibrium point (13), and we can analyse the

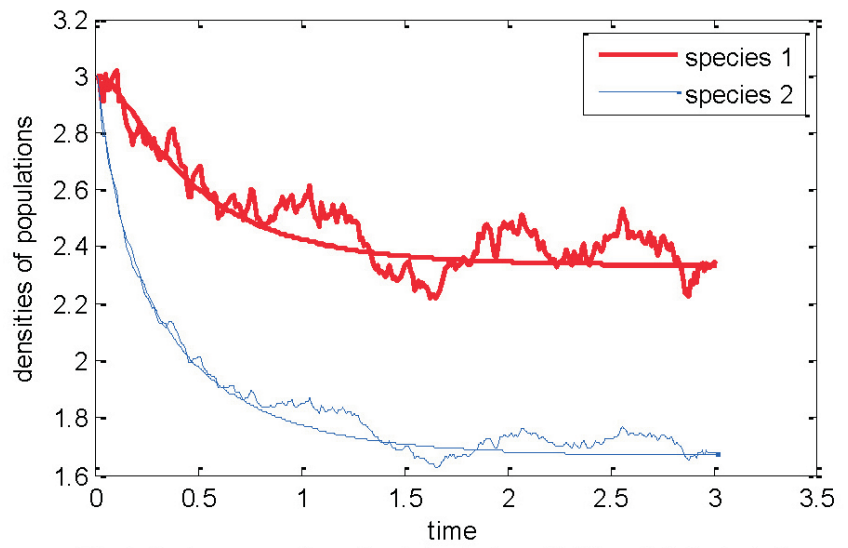

Fig. 4. Protocooperation: the trajectories of (11) and (11)+deviations: $\mathrm{g} 1=$ $3 ; \mathrm{g} 2=3 ; \mathrm{g} 3=1 ; \mathrm{m} 1=1 ; \mathrm{m} 2=2 ; \mathrm{m} 3=1$

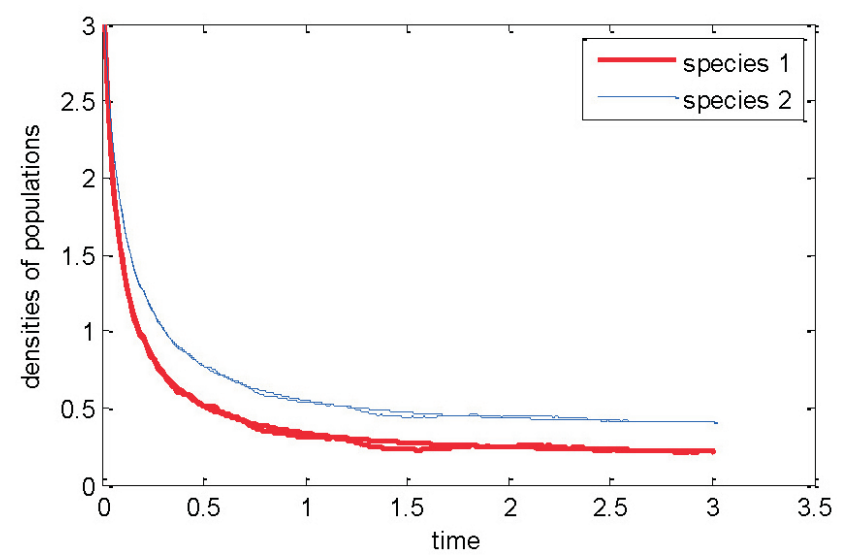

Fig. 5. Concurrence: the trajectories of (11) and (11)+deviations: $g 1=1$; $\mathrm{g} 2=3 ; \mathrm{g} 3=-1 ; \mathrm{m} 1=1 ; \mathrm{m} 2=2 ; \mathrm{m} 3=-1$ 


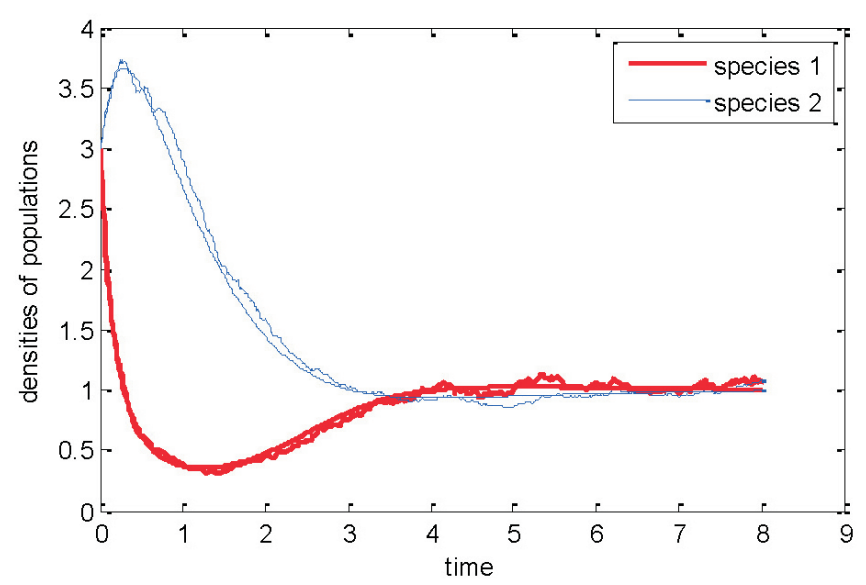

Fig. 6. Prey-predator: the trajectories of (11) and (11)+deviations: $g 1=3$; $\mathrm{g} 2=2 ; \mathrm{g} 3=-1 ; \mathrm{m} 1=-1 ; \mathrm{m} 2=0 ; \mathrm{m} 3=1$

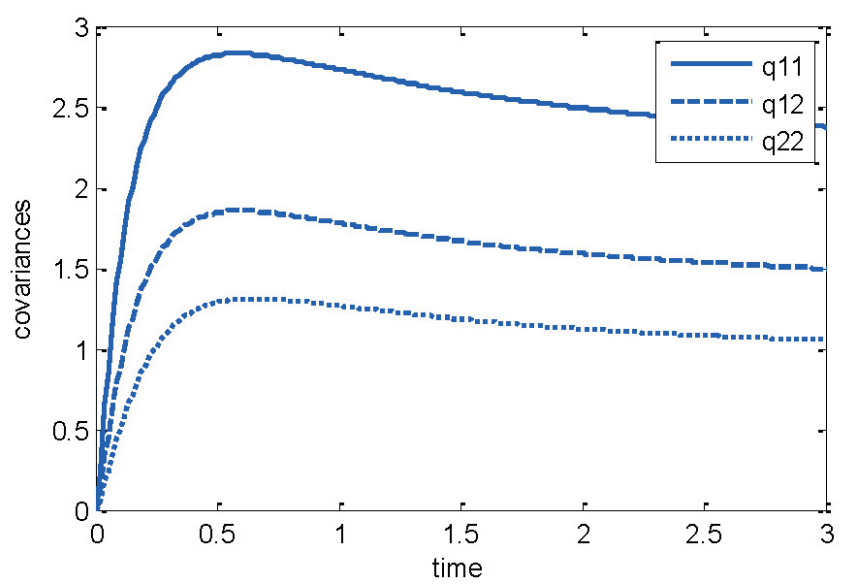

Fig. 7. The coordinates of covariance matrix. Protocooperation: $\mathrm{g} 1=3$; $\mathrm{g} 2=2 ; \mathrm{g} 3=1 ; \mathrm{m} 1=1 ; \mathrm{m} 2=2 ; \mathrm{m} 3=1$

asymptotics of (14) with $x(t) \equiv \bar{x}, y(t) \equiv \bar{y}$. The matrix $A(\bar{x}, \bar{y})$ is negative definite and we can look for the above-mentioned matrix $\bar{C}$ as the solution of the matrix equation

$A(\bar{x}, \bar{y}) \bar{C}+\bar{C} A^{T}(\bar{x}, \bar{y})+S(\bar{x}, \bar{y})=0$

This means that after some time we may approximate the distribution functions for the process $\left\{x_{\varepsilon}(t), y_{\varepsilon}(t)\right\}$ defined by equation (12) as corresponding the two-dimensional Gaussian distributions with mean $\{\bar{x}, \bar{y}\}$ and covariance ma$\operatorname{trix} \varepsilon \bar{C}$.

\section{REFERENCES}

Bazykin, A. D. (1998). Nonlinear Dynamics of Interacting Populations, World Scientific, Singapore. 193 pp.

Britton, N. F. (2005). Essential Mathematical Biology. Springer Undergraduate Mathematics Series. Springer. 335 pp.

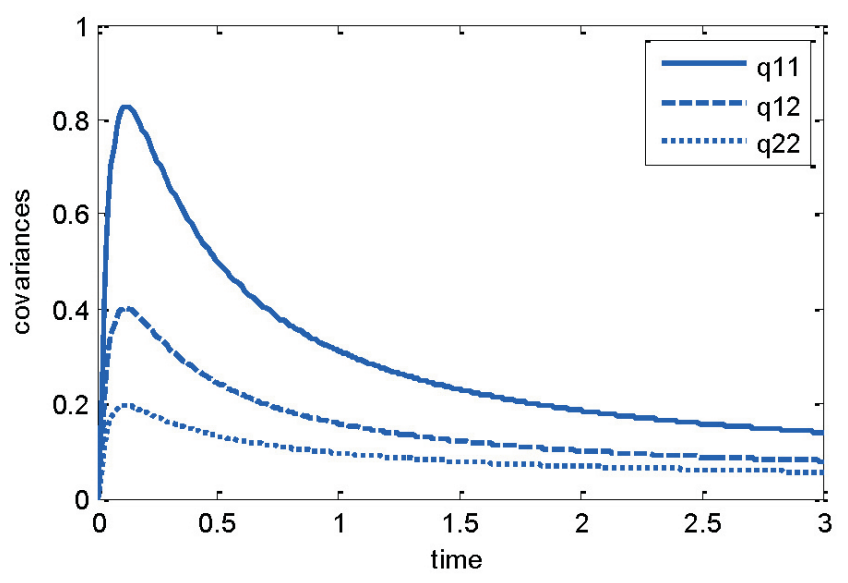

Fig. 8. The coordinates of covariance matrix. Concurrence: $\mathrm{g} 1=1 ; \mathrm{g} 2=3$; $\mathrm{g} 3=-1 ; \mathrm{m} 1=1 ; \mathrm{m} 2=2 ; \mathrm{m} 3=-1$

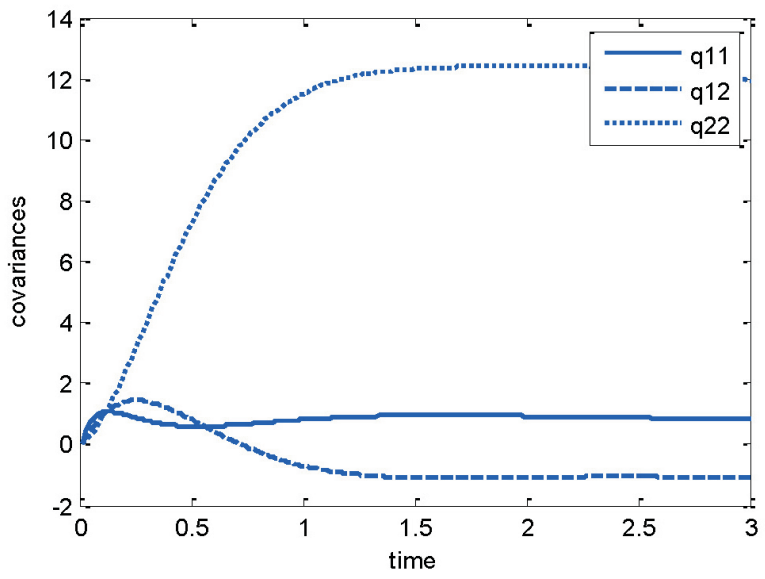

Fig. 9. The coordinates of covariance matrix. Prey-predator: $\mathrm{g} 1=3 ; \mathrm{g} 2=2$; $\mathrm{g} 3=-1 ; \mathrm{m} 1=-1 ; \mathrm{m} 2=0 ; \mathrm{m} 3=1$

Edelstein-Keshet, L. (2005). Mathematical Models in Biology. SIAM Classics in Applied Mathematics. 184 pp.

Gikhman, I. I., Skorokhod, A. V. (1972). Stochastic differential equations. Springer-Verlag, Berlin, Heidelberg. 356 pp.

Lotka, A. J. (1925). Elements of Physical Biology. Baltimore, Williams and Wilkins. 460 pp.

Mangel, M., Ludwig, D. (1977). Probability of extinction in a stochastic competition, SIAM J. Appl. Math., 33 (2), 256-266.

Murray, J. D. (2003). Mathematical Biology I: An Introduction. Vol. I. Springer-Verlag, 3rd edition. 576 pp.

Samanta, G. P. (2011). A stochastic two species competition model: nonequilibrium fluctuation and stability. Int. J. Stochastic Anal., 2011, Article ID 489386, 7 pages. Available from:

http://dx.doi.org/10.1155/2011/489386 (accessed 20.09.2019).

Skorokhod, A. V. (1989). Asymptotic Methods in the Theory of Stochastic Differential Equations (Transl. Math. Monographs 78). American Mathematical Society, Providence, RI. 339 pp.

Tsarkov, Ye. (Carkovs, J.) (2002). Asymptotic methods for stability analysis Markov impulse dynamical systems, Nonlinear Dynamics Syst. Theory, 2 (1), 103-115.

Volterra, V. (1931). Lefons sur la thiorie mathematique de la lutte pour la vie. Gauthier-Villars, Paris. 222 pp. 


\section{SAISTĪTO POPULĀCIJU DINAMIKAS STOHASTISKĀ MODELĒŠANA}

Rakstā apskatīts divu savstarpēji ietekmējošos populāciju matemātiskais modelis. Pieņemot, ka starp populācijām notiek ātri stohastiski kontakti, ir iegūti stohastiski Puasona tipa diferenciālvienādojumi ar mazu parametru un piedāvāts aproksimējošs algoritms populāciju dinamikas kvantitatīvai analīzei. To veido divi soḷi: vispirms ir atrasts parastais diferenciālvienādojums katras populācijas izaugsmes vidējai vērtībai un analizētas vidējā asimptotiskā populācijas lieluma izmaiņas; pēc tam, lietojot difūzijas aproksimācijas procedūru, iegūts Ito stohastiskais diferenciālvienādojums mazām gadījuma novirzēm no vidējām vērtībām lineāro nehomogēno Ito stohastisko diferenciālvienādojumu veidā un analizēti ar šo vienādojumu uzdotā Gausa procesa varbūtiskie raksturojumi. 